\title{
Glossary
}

\section{A glossary for social epidemiology}

\author{
N Krieger
}

Why "social epidemiology"? Is not all epidemiology, after all, "social” epidemiology? In so far as people are simultaneously social and biological organisms, is any biological process ever expressed devoid of social context? - or any social process ever unmediated by the corporal reality of our profoundly generative and mortal bodies? ${ }^{12}$ Yet, despite the seeming truism that social as well as biological processes inherently shape population health-a truism recognised even in the founding days of epidemiology as a scientific discipline in the early 19 th centurynot all epidemiology is "social epidemiology". ${ }^{4}$ Instead, "social epidemiology" (which first attained its name as such in English in $1950^{35}$ ) is distinguished by its insistence on explicitly investigating social determinants of population distributions of health, disease, and wellbeing, rather than treating such determinants as mere background to biomedical phenomena. Tackling this task requires attention to theories, concepts, and methods conducive to illuminating intimate links between our bodies and the body politic; toward this end, the glossary below provides a selection of critical terms for the field.

One brief note of explanation. Some entries contain only one term; others include several related terms whose meanings are interdependent or refer to specific aspects of a broader construct. Additionally, each entry is cast in relation to its significance to social epidemiology; explication of salience to other disciplines is beyond the scope of this particular glossary.

Biological expressions of social inequality Biological expressions of social inequality refers to how people literally embody and biologically express experiences of economic and social inequality, from in utero to death, thereby producing social inequalities in health across a wide spectrum of outcomes. ${ }^{126}$ Core to social epidemiology, this construct of "biological expressions of social inequality" has been evident in epidemiological thought-albeit not always explicitly named as such - since the discipline's emergence in the early 19th century, as exemplified by early pathbreaking research (for example, conducted by Louis René Villermé (1782-1863)) on socioeconomic gradients in-and effects of poverty onmortality, morbidity, and height. ${ }^{3} 78$

Examples include biological expressions of poverty and of diverse types of discrimination, for example, based on race/ethnicity, gender, sexuality, social class, disability, or age.
Whether these biological expressions of social inequality are interpreted as expressions of innate versus imposed, or individual versus societal, characteristics in part is shaped by the very social inequalities patterning population health. ${ }^{16}$ The construct of "biological expressions of social inequality" thus stands in contrast with biologically deterministic formulations that cast biological processes and traits tautologically invoked to define membership in subordinate versus dominant groups (for example, skin colour or biological sex) as explanations for social inequalities in health.

\section{Discrimination}

Discrimination refers to "the process by which a member, or members, of a socially defined group is, or are, treated differently (especially unfairly) because of his/her/their membership of that group"(page 169). ${ }^{9}$ This unfair treatment arises from "socially derived beliefs each [group] holds about the other" and "patterns of dominance and oppression, viewed as expressions of a struggle for power and privilege" (pages 125-6). ${ }^{10}$

People and institutions who discriminate adversely accordingly restrict, by judgement and action, the lives of those against whom they discriminate. ${ }^{6}$ At issue are practices of dominant groups - both institutionally and interpersonally - to maintain privileges they accrue through subordinating the groups they oppress (intentionally and also by maintaining the status quo) and the ideologies they use to justify these practices, with these ideologies revolving around notions of innate superiority and inferiority, difference, or deviance. ${ }^{6}$ Predominant types of adverse discrimination are based on race/ethnicity, gender, sexuality, disability, age, nationality, and religion, and, although not always recognised as such, social class. By contrast, positive discrimination (for example, affirmative action) seeks to rectify inequities created by adverse discrimination.

Social epidemiological analyses of health consequences of discrimination require conceptualising and operationalising diverse expressions of exposure, susceptibility, and resistance to discrimination, as listed below, recognising that individuals and social groups may be subjected simultaneously to multipleand interacting - types of discrimination: (page $42)^{6}$ 
Aspects of discrimination:

Type: defined in reference to constituent dominant and subordinate groups, and justifying ideology

Form: structural, institutional, interpersonal; legal or illegal; direct or indirect; overt or covert

Agency: perpetrated by state or by non-state actors (institutional or individuals)

Expression: from verbal to violent; mental, physical, or sexual

Domain: for example, at home; within family; at school; getting a job; at work; getting housing; getting credit or loans; getting medical care; purchasing other goods and services; by the media; from the police or in the courts; by other public agencies or social services; on the street or in a public setting

Level: individual, institutional, residential neighbourhood, community, political jurisdiction, national, regional, global

Cumulative exposure to discrimination:

Timing: intrauterine period; infancy; childhood; adolescence; adulthood

Intensity: severe to mild

Frequency: chronic; acute; sporadic

Duration: timespan over which discrimination is experienced

Responses to discrimination can similarly be analysed. ${ }^{6}$

\section{Ecosocial theory of disease distribution}

Ecosocial $^{12}$ and other emerging multi-level epidemiological frameworks ${ }^{11}{ }^{12}$ seek to integrate social and biological reasoning and a dynamic, historical and ecological perspective to develop new insights into determinants of population distributions of disease and social inequalities in health. The central question for ecosocial theory is: "who and what is responsible for population patterns of health, disease, and wellbeing, as manifested in present, past, and changing social inequalities in health?" Adequate epidemiological explanations accordingly must account for both persisting and changing distributions of disease, including social inequalities in health, across time and space. To aid conceptualisation, ecosocial theory uses a visual fractal metaphor of an evolving bush of life intertwined with the scaffolding of society that different core social groups daily reinforce or seek to alter. ${ }^{12} \mathrm{~A}$ fractal metaphor is chosen because fractals are recursive structures, repeating and self similar at every scale, from micro to macro. ${ }^{2}$ Thus, ecosocial theory invites consideration of how population health is generated by social conditions necessarily engaging with biological processes at every spatiotemporal scale, whether from subcellular to global, or nanoseconds to millenniums. ${ }^{1}$

Core concepts for ecosocial theory accordingly include ${ }^{1}$ :

(1) embodiment, a concept referring to how we literally incorporate, biologically, the material and social world in which we live, from in utero to death; a corollary is that no aspect of our biology can be understood absent knowledge of history and individual and societal ways of living.
(2) pathways of embodiment, structured simultaneously by: (a) societal arrangements of power and property and contingent patterns of production, consumption, and reproduction, and (b) constraints and possibilities of our biology, as shaped by our species' evolutionary history, our ecological context, and individual histories, that is, trajectories of biological and social development.

(3) cumulative interplay between exposure, susceptibility, and resistance, expressed in pathways of embodiment, with each factor and its distribution conceptualised at multiple levels (individual, neighbourhood, regional or political jurisdiction, national, inter-national or supra-national) and in multiple domains (for example, home, work, school, other public settings), in relation to relevant ecological niches, and manifested in processes at multiple scales of time and space.

(4) accountability and agency, expressed in pathways of and knowledge about embodiment, in relation to institutions (government, business, and public sector), communities, households, and individuals, and also to accountability and agency of epidemiologists and other scientists for theories used and ignored to explain social inequalities in health; a corollary is that, given likely complementary causal explanations at different scales and levels, epidemiological studies should explicitly name and consider the benefits and limitations of their particular scale and level of analysis.

More than simply adding "biology" to "social" analyses, or "social factors" to "biological" analyses, the ecosocial framework begins to envision a more systematic integrated approach capable of generating new hypotheses, rather than simply reinterpreting factors identified by one approach (for example, biological) in terms of another (for example, social).

\section{Embodiment}

A core concept for understanding relationships between the state of our bodies and the body politic; see definition in entry on "ecosocial theory"

\section{Gender, sexism, and sex}

Gender refers to a social construct regarding culture-bound conventions, roles, and behaviours for, as well as relationships between and among, women and men and boys and girls. ${ }^{13-15}$ Gender roles vary across a continuum and both gender relationships and biological expressions of gender vary within and across societies, typically in relation to social divisions premised on power and authority (for example, class, race/ethnicity, nationality, religion). ${ }^{6}{ }^{15}$ Sexism, in turn, involves inequitable gender relationships and refers to institutional and interpersonal practices whereby members of dominant gender groups (typically men) accrue privileges by subordinating other gender groups (typically women) and justify these practices via ideologies of innate superiority, difference, or deviance. ${ }^{6}{ }^{13-15}$ Lastly, sex is a biological construct premised upon biological characteristics 
enabling sexual reproduction. ${ }^{14}{ }^{16}$ Among people, biological sex is variously assigned in relation to secondary sex characteristics, gonads, or sex chromosomes; sexual categories include: male, female, intersexual (persons born with both male and female sexual characteristics), and transsexual (persons who undergo surgical and/or hormonal interventions to reassign their sex). ${ }^{14}$ Sex linked biological characteristics (for example, presence or absence of ovaries, testes, vagina, penis; various hormone levels; pregnancy, etc) can, in some cases, contribute to gender differentials in health but can also be construed as gendered expressions of biology and erroneously invoked to explain biological expressions of gender. ${ }^{16}$ For example, associations between parity and incidence of melanoma among women are typically attributed to pregnancy related hormonal changes; new research indicating comparable associations between parity and incidence of melanoma among men, however, suggests that social conditions linked to parity, and not necessarily - or solely - the biology of pregnancy, may be aetiologically relevant. ${ }^{17}$

\section{Human rights and social justice}

Human rights, as a concept, presumes that all people "are born free and equal in dignity and rights" ${ }^{18}$ and provides a universal frame of reference for deciding questions of equity and social justice. ${ }^{18-21}$ Operationally, translated to the realm of political and legal accountability, "international human rights law is about defining what governments can do to us, cannot do to us, and should do for us" 19 [italics in the original], so as to respect, protect, and fulfill their human rights obligations. ${ }^{19} 20$ Human rights norms are premised, in the first instance, upon the 1948 Universal Declaration of Human Rights ${ }^{18}$ and its recognition of the indivisibility and interdependence of civil, political, economic, social, and cultural rights. ${ }^{18-21} \mathrm{~A}$ "health and human rights" framework thus not only spurs recognition of how realisation of human rights promotes health but also helps translate concerns about how violation of human rights potentially harms health into concrete and actionable grievances that governments and the international community are legally and politically required to address. Understanding of what prompts violation of human rights and sustains their respect, protection and fulfillment is, in turn, aided by social justice frameworks, which explicitly analyse who benefits from-and who is harmed by-economic exploitation, oppression, discrimination, inequality, and degradation of "natural resources". ${ }^{21-24}$ Together, both frameworks provide concepts relevant for analysing social determinants of health and for guiding action to create just and sustainable societies.

\section{Lifecourse perspective}

Lifecourse perspective refers to how health status at any given age, for a given birth cohort, reflects not only contemporary conditions but embodiment of prior living circumstances, in utero onwards. ${ }^{25-27}$ At issue are people's developmental trajectories (both biological and social) over time, as shaped by the historical period in which they live, in reference to their society's social, economic, political, technological, and ecological context. One component may involve what has been termed "biological programming", referring to "the process whereby a stimulus or insult, at a sensitive or "critical" period of development, has lasting or lifelong significance" (page 13) ${ }^{27}$; which of these processes, under what circumstances, are reversible is an important empirical and public health question.

\section{Multi-level analysis}

Multi-level analysis refers to statistical methodologies, first developed in the social sciences, which analyse outcomes simultaneously in relation to determinants measured at different levels (for example, individual, workplace, neighborhood, nation, or geographical region existing within or across geopolitical boundaries). ${ }^{28-31}$ If guided by well developed conceptual models clearly specifying which variables are to be studied at which level, ${ }^{28}$ these analyses can potentially assess whether individuals' health is shaped by not only "individual" or "household" characteristics (for example, individual or household income) but also "population" or "area" characteristics; the latter may be "compositional" (for example, proportion of people living in poverty) or "contextual" (irreducible to the individual level, for example, income distribution, population density, or absence of facilities, such as supermarkets, libraries, or health centres). ${ }^{30} 31$

\section{Poverty, deprivation (material and} social), and social exclusion

To be impoverished is to lack or be denied adequate resources to participate meaningfully in society. A complex construct, poverty is inherently a normative concept that can be defined-in both absolute and relative terms - in relation to: "need", "standard of living", "limited resources", "lack of basic security", "lack of entitlement", "multiple deprivation", “exclusion", “inequality", "class", "dependency", and "unacceptable hardship" 32 ; see "socioeconomic position" (below). Also relevant is whether the experience of poverty is transient or chronic.

According to the United Nations, as elaborated in the Human Development Report 2000, two forms of poverty can be distinguished: "human poverty" and "income poverty" (page 17). ${ }^{21}$ Human poverty is "defined by impoverishment in multiple dimensions-deprivations in a long and healthy life, in knowledge, in a decent standard of living, in participation"; income poverty, by contrast, "is defined by deprivation in a single dimension-income" (page $17 .^{21}$ From this perspective, income poverty constitutes a critical (but not exclusive) determinant of human poverty, including the latter's expression in compromised health status.

Deprivation (pages $10-11,36-37)^{33}$ can be conceptualised and measured, at both the individual and area level, in relation to: material deprivation, referring to "dietary, clothing, housing, home facilities, environment, location 
and work (paid and unpaid)," and social deprivation, referring to rights in relation to "employment, family activities, integration into the community, formal participation in social institutions, recreation and education"(page 93). ${ }^{34}$

Poverty thresholds accordingly can be set at: (a) an income level (for example, poverty line) determined inadequate for meeting subsistence needs, or (b) "the point at which resources are so seriously below those commanded by the average individual or family that the poor are, in effect, excluded from ordinary living patterns, customs, and activities", such that the poverty line equals "the point at which withdrawal escalates disproportionately to the falling resources" (pages 116-17). ${ }^{33}$

Social exclusion, another term encompassing aspects of poverty, in turn focuses attention on not only the impact but also the process of marginalisation (pages 54-6). ${ }^{33}{ }^{35}$ Avenues by which social groups and individuals can become excluded from full participation in social and community life include: (a) legal exclusion (for example, de jure discrimination), (b) economic exclusion (due to economic deprivation), (c) exclusion due to lack of provision of social goods (for example, no translation services or lack of facilities for disabled persons), and (d) exclusion due to stigmatisation (for example, of persons with HIV/AIDS) and de facto discrimination.

\section{Psychosocial epidemiology}

A psychosocial framework directs attention to both behavioural and endogenous biological responses to human interactions. ${ }^{1}$ At issue is the "health-damaging potential of psychological stress", as "generated by despairing circumstances, insurmountable tasks, or lack of social support" (page 41) ${ }^{36}$; see also "stress" (below). Typically conceptualised in relation to individuals, its central hypothesis is that chronic and acute social stressors: (a) alter host susceptibility or become directly pathogenic by affecting neuroendocrine function, and/or (b) induce health damaging behaviours (especially in relation to use of psychoactive substances, diet, and sexual behaviours). ${ }^{14} 36$ "Social capital" and "social cohesion", in turn, are proposed (and contested) as population level psychosocial assets that potentially can improve population health by influencing norms and strengthening bonds of "civil society", with the caveat that membership in certain social formations can potentially harm either members of the group (for example, group norms encourage high risk behaviours) or non-group members (for example, harm caused to groups subjected to discrimination by groups supporting discrimination). ${ }^{137-40}$

\section{Race/ethnicity and racism}

Racelethnicity is a social, not biological, category, referring to social groups, often sharing cultural heritage and ancestry, that are forged by oppressive systems of race relations, justified by ideology, in which one group benefits from dominating other groups, and defines itself and others through this domination and the possession of selective and arbitrary physical characteristics (for example, skin colour). ${ }^{6}{ }^{13}$ Racism refers to institutional and individual practices that create and reinforce oppressive systems of race relations (see "discrimination", above). ${ }^{61541}$ Ethnicity, a construct originally intended to discriminate between "innately" different groups allegedly belonging to the same overall "race", ${ }^{42} 43$ is now held by some to refer to groups allegedly distinguishable on the basis of "culture" ${ }^{44}$; in practice, however, "ethnicity" cannot meaningfully be disentangled from "race" in societies with inequitable race relations, hence the construct "race/ ethnicity". ${ }^{42}$

Two diametrically opposed constructs are thus relevant to understanding research on and explaining racial/ethnic disparities in health. ${ }^{6}{ }^{45}$ The first is: racialised expressions of biology, whereby measured average biological differences between members of diverse racial/ethnic groups are assumed to reflect innate, genetically determined differences (premised, in the first instance, on the arbitrary phenotypic characteristics seized upon to define, tautologically, racial categories). The second is: biological expressions of racism (see "biological expressions of social inequality", above). For example, following dominant ideas construing "race" as an innate biological characteristic, epidemiological research has been rife with studies attempting to explain racial/ethnic disparities in health in relation to presumed genetic differences, absent consideration of effects of racism on health. ${ }^{64-4647}$ Alternatively, considering lived experiences of racism as real but the construct of biological "race" as spurious, social epidemiological research investigates health consequences of economic and non-economic expressions of racial discrimination. ${ }^{6}{ }^{13} 45-48$

\section{Sexualities and heterosexism}

Sexuality refers to culture bound conventions, roles, and behaviours involving expressions of sexual desire, power, and diverse emotions, mediated by gender and other aspects of social position (for example, class, race/ethnicity, etc). ${ }^{49}$ Distinct components of sexuality include: sexual identity, sexual behaviour, and sexual desire. Contemporary "Western" categories by which people self identify or can be labelled include: heterosexual, homosexual, lesbian, gay, bisexual, "queer", transgendered, transsexual, and asexual. Heterosexism, the type of discrimination related to sexuality, constitutes one form of abrogation of sexual rights ${ }^{50}$ and refers to institutional and interpersonal practices whereby heterosexuals accrue privileges (for example, legal right to marry and to have sexual partners of the "other" sex) and discriminate against people who have or desire same sex sexual partners, and justify these practices via ideologies of innate superiority, difference, or deviance. Lived experiences of sexuality accordingly can affect health by pathways involving not only sexual contact (for example, spread of sexually transmitted disease) but also discrimination and material conditions of family and household life. ${ }^{49} 50$ 
Society, social, societal, and culture Society, originally meaning "companionship or fellowship", now stands as "our most general term for the body of institutions and relationships within which a relatively large group of people live and as our most abstract term for the condition in which such institutions and relationships are formed"(page 291)..$^{51}$ Social, as an adjective, likewise has complex meanings: "as a descriptive term for society in its now predominant sense of the system of common life", and also as "an emphatic and distinguishing term, explicitly contrasted with individual and especially individualist theories of society" (page 286) [italics in the original]..$^{51}$ Societal, in turn, serves as a "more neutral reference to general social formations and institutions" (page 294). ${ }^{51}$ By this logic, social epidemiology and its social theories of disease distribution stand in contrast to individualistic epidemiology, which relies on individualistic theories of disease causation (see "theories of disease distribution", below).

Culture, originally a "noun of process" referring to "the tending of something, basically crops or animals," (page 87$)^{51}$ presently has three distinct meanings: "(i) the independent and abstract noun which describes a general process of intellectual, spiritual, and aesthetic development . . .; (ii) the independent noun, whether used generally or specifically, which indicates a particular way of life, whether of a people, a period, a group, or humanity in general; and ... (iii) the independent and abstract noun which describes the work and practices of intellectual and especially artistic activity" (page 90). ${ }^{51}$ In social epidemiology, meaning (ii) predominates, with "culture" typically conceptualised and operationalised in relation to health related beliefs and practices, especially dietary practices. By this logic, "acculturation" (or, perhaps more accurately "deculturation" ${ }^{45}$ ) refers to members of one "culture" adopting beliefs and practices of another (and typically dominant) "culture". 5253 Related, examples abound ${ }^{44}$ in epidemiological literature whereby the construct of "culture" is conflated with "ethnicity" (and "race") and together are inappropriately invoked to explain socioeconomic and health characteristics of diverse population groups on the basis of "innate" qualities, rather than as a consequence of inequitable social relationships between groups. ${ }^{52}$

Social class and socioeconomic position Social class refers to social groups arising from interdependent economic relationships among people (pages 60-69). ${ }^{5154-56}$ These relationships are determined by a society's forms of property, ownership, and labour, and their connections through production, distribution, and consumption of goods, services, and information. Social class is thus premised upon people's structural location within the economy - as employers, employees, self employed, and unemployed (in both the formal and informal sector), and as owners, or not, of capital, land, or other forms of economic investments. Stated simply, classes-like the working class, business owners, and their managerial class-exist in relationship to and co-define each other. One cannot, for example, be an employee if one does not have an employer and this distinction-between employee and employer-is not about whether one has more or less of a particular attribute, but concerns one's relationship to work and to others through a society's economic structure. Class, as such, is not an a priori property of individual human beings, but is a social relationship created by societies. As such, social class is logically and materially prior to its expression in distributions of occupations, income, wealth, education, and social status. One additional and central component of class relations entails an asymmetry of economic exploitation, whereby owners of resources (for example, capital) gain economically from the labour or effort of non-owners who work for them.

Socioeconomic position, in turn, is an aggregate concept that includes both resource-based and prestige-based measures, as linked to both childhood and adult social class position. ${ }^{54-56}$ Resource-based measures refer to material and social resources and assets, including income, wealth, and educational credentials; terms used to describe inadequate resources include "poverty" and "deprivation" (see "poverty", above). Prestige-based measures refer to individuals' rank or status in a social hierarchy, typically evaluated with reference to people's access to and consumption of goods, services, and knowledge, as linked to their occupational prestige, income, and educational level. Given distinctions between resource-based and prestige-based aspects of socioeconomic position and the diverse pathways by which they affect health, epidemiological studies should state clearly how measures of socioeconomic position are conceptualised. The term "socioeconomic status" should be eschewed because it arbitrarily (if not intentionally) privileges "status"-over material resources-as the key determinant of socioeconomic position. ${ }^{54}$

\section{Social determinants of health}

Social determinants of health refer to both specific features of and pathways by which societal conditions affect health and that potentially can be altered by informed action. ${ }^{4245}$ As determinants, these social processes and conditions are conceptualised as "essential factors" that "set certain limits or exert pressures", albeit without necessarily being "deterministic" in the sense of "fatalistic determinism" (pages 98-102). ${ }^{51}$

Historically contingent, social determinants of health, broadly writ, include:

(a) a society's past and present economic, political, and legal systems, its material and technological resources, and its adherence to norms and practices consistent with international human rights norms and standards; and

(b) its external political and economic relationships to other countries, as implemented through interactions among governments, international political and economic 
organisations (for example, United Nations, World Bank, International Monetary Fund), and non-governmental organisations.

One term appearing in social epidemiological literature to summarise social determinants of health is "social environment". ${ }^{757}$ This metaphor invokes notions of "environment", a term literally referring to "surroundings" and initially used to denote the physical, including both "natural" and "built", environment. Both "social environment" and the related metaphor "social ecology" are problematic in that they can conceal the role of human agency in creating social conditions that constitute social determinants of health. ${ }^{1}$

\section{Social inequality or inequity in health and social equity in health}

Social inequalities (or inequities) in health refer to health disparities, within and between countries, that are judged to be unfair, unjust, avoidable, and unnecessary (meaning: are neither inevitable nor unremediable) and that systematically burden populations rendered vulnerable by underlying social structures and political, economic, and legal institutions. ${ }^{21} 5859$ As such, social inequalities (or inequities) in health are not synonymous with "health inequalities", as this latter term can be interpreted to refer to any difference and not specifically to unjust disparities. ${ }^{58} 59$ For example, recently proposed measures of "health inequalities" deliberately quantify distributions of health in populations without reference to either social groups and or social inequalities in health..$^{59-62}$

Social equity in health, in turn, refers to an absence of unjust health disparities between social groups, within and between countries. ${ }^{58}$ Promoting equity and diminishing inequity requires not only a "process of continual equalization" but also a "process of abolishing or diminishing privileges" (pages 117-19)..$^{51}$ Thus, pursuing social equity in health entails reducing excess burden of ill health among groups most harmed by social inequities in health, thereby minimising social inequalities in health and improving average levels of health overall. $^{21}$

\section{Social production of disease/political economy of health}

Social production of disease/political economy of health refers to related (if not identical) theoretical frameworks that explicitly address economic and political determinants of health and distributions of disease within and across societies, including structural barriers to people living healthy lives. ${ }^{163-66}$ These theories accordingly focus on economic and political institutions and decisions that create, enforce, and perpetuate economic and social privilege and inequality, which they conceptualise as root-or "fundamental" 67 - causes of social inequalities in health. Although compatible with the ecosocial theory of disease distribution, they differ in that they do not systematically seek to integrate biological constructs into explanations of social patternings of health. ${ }^{12}$
Social production of scientific knowledge Social production of scientific knowledge refers to ways in which social institutions and beliefs affect recruitment, training, practice, and funding of scientists, thereby shaping what questions we, as scientists, do and do not ask, the studies we do and do not conduct, and the ways in which we analyse and interpret data, consider their likely flaws, and disseminate results. ${ }^{68-71}$

That scientists' ideas are shaped, in part, by dominant social beliefs of their times is well documented. ${ }^{372-74}$ Relevant to social epidemiology, a substantial body of literature demonstrates how scientific knowledge and, more importantly, real people, have been harmed by scientific racism, sexism and other related ideologies, including eugenics, which justify discrimination and discount the importance of understanding and ameliorating social inequalities in health. ${ }^{6}$ Tellingly, as of the year 2000 , only $0.05 \%$ of the approximately 34000 articles indexed in Medline by the keyword "race" had explicitly investigated racial discrimination as a determinant of population health. ${ }^{6}$

\section{Stress}

Stress, a term widely used in the biological, physical, and social sciences, is a construct whose meaning in health research is variously defined in relationship to "stressful events, responses, and individual appraisals of situations" (page 3). ${ }^{75}$ Common to these definitions is "an interest in the process in which environmental demands tax or exceed the adaptive capacity of an organism, resulting in psychological or biological changes that may place persons at risk for disease" [italics in original] (page 3). ${ }^{75} \mathrm{An}$ "environmental stress perspective" focuses on "environmental demands, stressors, or events" (page 4) ${ }^{75}$; a "psychological stress perspective", on "an organism's perception and evaluation of the potential harm posed by objective environmental exposures" (page 6) ${ }^{75}$; a "biological stress perspective", on "activation of the physiological systems that are particularly responsive to physical and psychological demands" (page 8). ${ }^{75}$ Whether social epidemiological research conceptualises stress in relation to structural, interpersonal, cognitive, or biological parameters, and whether it uses "environment" as a term or metaphor that reveals or conceals the role of human agency and accountability in determining distributions of "stress", depends on the underlying theories of disease distribution guiding the research (see "theories of disease distribution", below, and "social determinants", above).

\section{Theories of disease distribution}

Theories of disease distribution seek to explain current and changing population patterns of disease across time and space and, in the case of social epidemiology, across social groups (within and across countries, over time). ${ }^{1}$ Using - like any theory (pages 316-18) ${ }^{51}{ }^{71}$-interrelated sets of ideas whose plausibility can be tested by human action and thought, theories of disease distribution presume but cannot be reduced to mechanism oriented theories of disease causation. ${ }^{1}$ 
Explicit attention to aetiological theory is essential, because shared observations of social disparities in health do not necessarily translate to common understandings of causes. ${ }^{1}$ Excess risk of HIV/AIDS among poor women of colour, for example, is attributed to social inequity by ecosocial and social production of disease theories of disease distribution, but is attributed to "bad behaviours" by biomedical lifestyle theories of disease causation. ${ }^{176}$

Thanks to Sofia Gruskin, Mary Northridge, and George Davey Smith for helpful comments.

1 Krieger N. Emerging theories for social epidemiology in the 21 st century: an ecosocial perspective. Int $\mathcal{F}$ Epidemiol (in press).

2 Krieger N. Epidemiology and the web of causation: has anyone seen the spider? Soc Sci Med 1994;39:887-903.

3 Krieger N. Epidemiology and social sciences: towards a critical reengagement in the 21 st century. Epidemiol Rev 2000;11:155-63.

4 Berkman L, Kawachi I, eds. Social epidemiology. Oxford: Oxford University Press, 2000

5 Yankauer A. The relationship of fetal and infant mortality to residential segregation: an inquiry into social epidemiology. Am Sociol Review 1950;15:644-8.

6 Krieger N. Discrimination and health. In: Berkman L, Kawachi I, eds. Social epidemiology. Oxford: Oxford University Press, 2000:36-75.

7 Sydenstricker E. Health and environment. New York: McGraw-Hill, 1933.

8 Morris JN. Uses of epidemiology. Edinburgh: Livingston, 1957

9 Jary D, Jary J, eds. Collins dictionary of sociology. 2nd ed. Glasgow, UK: HarperCollins Publishers, 1995.

10 Marshall G, ed. The concise Oxford dictionary of sociology. Oxford: Oxford University Press, 1994.

11 Susser M, Susser E. Choosing a future for epidemiology: II. from black boxes to Chinese boxes and eco-epidemiology. Am 7 Public Health 1996;86:674-7.

12 McMichael AJ. Prisoners of the proximate: loosening the constraints on epidemiology in an age of change. Am $\mathcal{F}$ Epidemiol 1999:149:887-97.

13 Krieger N, Rowley DL, Herman AA, et al. Racism, sexism, and social class: implications for studies of health, disease, and well-being. Am f Prev Med 1993;9 (suppl):82-122.

14 Fausto-Sterling A. Sexing the body: gender politics and the construction of sexuality. New York: Basic Books, 2000.

15 Essed P. Diversity: gender, color, and culture. Amherst, MA University of Massachusetts, 1996.

16 Ruiz MT, Verbrugge LM. A two way view of gender bias in medicine. F Epidemiol Community Health 1997;51:106-9.

17 Kravdal O. Is the relationship between childbearing and cancer incidence due to biology or lifestyle? Examples of the importance of using data on men. Int f Epidemiol 1995; 4:477-84.

18 United Nations. Universal declaration of human rights. GA Res 217A(III), UN GAOR, Res 71, UN Doc A/810, 1948.

19 Gruskin S, Tarantola D. Health and human rights. In: Detels R, McEwen J, Beaglehole R, et al, eds. The Oxford textbook of public health. 4th ed. New York: Oxford University Press (in press)

20 Mann JM, Gruskin S, Grodin MA, et al, eds. Health and human rights. New York: Routledge, 1999

21 UNDP 2000: United Nations Development Programme (UNDP). Human development report 2000: Human rights and human development. New York: Oxford University Press, 2000.

22 Boucher D, Kelly P, ed. Social justice: from Hume to Walzer. London: Routledge, 1998.

23 Krieger N, Birn A-E. A vision of social justice as the foundation of public health: commemorating 150 years of the Spirit of 1848. Am ₹ Public Health 1998;88:1603-6.

24 People's Health Assembly 2000. People's charter for health. Gonoshasthaya Kendra, Savar, Bangladesh December 4-8, 2000. At: http://www.pha2000.org [last accessed: 11 Feb 2000.

25 Kuh D

26 disease epidemiology. Oxford: Oxford University Press, 1997. approaches to socio-economic differentials in causespecific adult mortality. In: Leon D, Walt G, eds. Poverty, inequality, and health: an international perspective. Oxford: Oxford University Press, 2001:88-124

27 Barker DJP. Mothers, babies, and health in later life. 2nd ed. Edinburgh: Churchill Livingston, 1998.

28 Blalock HM Jr. Contextual-effects models: theoretic and methodologic issues. Annu Review Sociol 1984;10:353-72.

29 Bryk AS, Raudenbush SW. Hierarchical linear models: applications and data analysis methods. Newbury Park, CA: Sage, 1992.

30 Diez-Roux AV. Bringing context back into epidemiology: variables and fallacies in multilevel analysis. Am F Public Health 1998;88:216-22.

31 Macintyre S, Ellaway A. Ecological approaches: rediscovering the role of the physical and social environment. In:
Berkman L, Kawachi I, eds. Social epidemiology. Oxford: Oxford University Press, 2000:332-48.
32 Spicker P. Definitions of poverty: eleven clusters of glossary on poverty. London: Zed Books, 1999:150-62.

33 Gordon D, Spicker P, eds. The international glossary on poverty. London: Zed Books, 1999

34 Townsend P. The international analysis of poverty. New York: Harvester/Wheatsheaf, 1993.

35 Shaw M, Dorling D, Davey Smith G. Poverty, social exclusion, and minorities. In: Marmot M, Wilkinson RG, eds. Social determinants of health. Oxford: Oxford University Press, 1999:211-39.

36 Elstad JI. The psycho-social perspective on social inequalities in health. In: Bartley M, Blane D, Davey Smith G, eds. The sociology of health inequalities. Oxford: Blackwell, 1998: $39-58$.

37 Kawachi I, Berkman L. Social cohesion, social capital, and health. In: Berkman L, Kawachi I, eds. Social epidemiology. Oxford: Oxford University Press, 2000:174-90.

38 Wilkinson RG. Unhealthy societies: the afflictions of inequality. London: Routledge, 1996.

39 Lynch JW, Davey Smith G, Kaplan GA, House JS. Income inequality and mortality: importance to health of individual incomes, psychological environment, or material conditions. $B M \mathcal{F} 2000 ; 320: 1200-4$.

40 Kunitz SJ. Accounts of social capital: the mixed health effects of personal communities and voluntary groups. In: Leon D, Walt G, eds. Poverty, inequality, and health: an international perspective Oxford: Oxford University Press, 2001:159-74.

41 Essed P. Understanding everyday racism: an interdisciplinary heory. London: Sage, 1992.

42 Statistics Canada and US Bureau of the Census. Challenges of measuring in an ethnic world: Science, politics, and reality. Washington, DC: US Government Printing Office, 1993.

43 Hobsbawm EJ. Nations and nationalism since 1780: programme, myth, reality. 2nd ed. Cambridge: Cambridge University Press, 1992.

44 Haynes MA, Smedley BD, eds. The unequal burden of cancer: an assessment of NIH research and programs for ethnic minorities and the medically underserved. Washington, DC: ties and the medically underser.

45 Krieger N. Refiguring "race": epidemiology, racialized biology, and biological expressions of race relations. Int $\mathcal{F}$
Health Services 2000;30:211-16.

46 Williams DR. Race, socioeconomic status, and health. The added effects of racism and discrimination. Ann NY Acad Sci 1999;896:173-88.

47 Lillie-Blanton M, LaVeist T. Race/ethnicity, the social environment, and health. Soc Sci Med 1996;43:83-92.

48 Davey Smith G. Learning to live with complexity: ethnicity, socioeconomic position, and health in Britain and the United States. Am 7 Public Health 2000;90:1694-8.

49 Parker RG, Gagnon JH, eds. Conceiving sexuality: approaches to sex research in a post-modern world. New York: Routledge, 1995.

50 Miller AM. Sexual but not reproductive: exploring the junction and disjunction of sexual and reproductive rights. Health and Human Rights 2000;4:68-109.

51 Williams R. Keywords: a vocabulary of culture and society. Revised ed. New York: Oxford University Press, 1983.

52 Kunitz SJ. Disease and social diversity: the European impact on the health of non-Europeans. New York: Oxford University Press, 1994

53 Lin SS, Kelsey JL. Use of race and ethnicity in epidemiologic research: concepts, methodologic issues, and suggestions for research. Epidemiol Rev 2000;22:187-202.

54 Krieger N, Williams D, Moss N. Measuring social class in US public health research: concepts, methodologies and guidelines. Annu Rev Public Health 1997;18:341-78.

55 Wright EO. Class counts: comparative studies in class analysis. New York: Cambridge University Press, 1997.

56 Lynch J, Kaplan G. Socioeconomic position. In: Berkman L, Kawachi I, eds. Social epidemiology. Oxford: Oxford University Press, 2000:13-35.

57 Marmot M, Wilkinson RG, eds. Social determinants of health. Oxford: Oxford University Press, 1999.

58 Whitehead $M$. The concepts and principles of equity and health. Int $\mathcal{F}$ Health Services 1992;22:429-45.

59 Leon DA, Walt G, Gilson L. International perspectives on health inequalities and policy. BMF 2001;332:591-4.

60 Murray C, Gakidou EE, Frenk J. Health inequalities and social group differences: what should we measure? Bull WHO 1999;77:537-43.

61 Murray CIL, Frenk J, Gadikou EE. Measuring health inequality: challenges and new directions. In: Leon D, Walt G, eds. Poverty, inequality, and health: an international perspective. Oxford: Oxford University Press, 2001:194-216.

62 Braveman P, Krieger N, Lynch J. Health inequalities and social inequalities in health. Bull WHO 2000;78:232-4

63 Doyal L. The political economy of health. London: Pluto Press, 1979 (1935).

64 Breilh J. Epidemiologia economia medicina y politica. 4th ed. Mexico City, Mexico: Distribuciones Fontamara, 1988

65 Conrad P, Kern R, eds. The sociology of health and illness: critical perspectives. New York: St Martin's Press, 1981.

66 Navarro V. Crisis, health, and medicine: a social critique. New York: Tavistock, 1986

67 Link BG, Phelan JC. Editorial: understanding sociodemographic differences in health - the role of fundamental social causes. Am f Public Health 1996;86:471-3.

68 Fleck L. Genesis and development of a scientific fact. Chicago: Fleck L. Genesis and development of a scientific fact.
University of Chicago University Press, 1979.

69 Rose H, Rose S, eds. Ideology of/in the natural sciences. Cambridge, MA: Schenkman, 1979. 
70 Haraway D. Primate visions: gender, race, and nature in the world of modern science. New York: Routledge, 1989.

71 Ziman JM Real science: what it is, and what it means. Cambridge: Cambridge University Press, 2000.

72 Fee E. Disease and discovery: a history of the 7ohns Hopkin Fee E. Disease and discovery: a history of the Fohns Hopkins
School of Hygiene and Public Health, 1916-1936. Baltimore: Johns Hopkins University Press, 1987.

73 Rosenberg CD, Golden J, eds. Framing disease: studies in cultural history. New Brunswick, NJ: Rutgers University Press, 1992.
74 Porter D. Health, civilization, and the state: a history of public health from ancient to modern times. London: Routledge, health

75 Cohen S, Kessler RC, Underwood L. Measuring stress: a guide for health and social scientists. New York: Oxford University Press, 1995.

76 Fee E, Krieger N. Understanding AIDS: historical interpretations and the limits of biomedical individualism. Am $\mathcal{F}$ Public Health 1993;83:1477-86.

\title{
7th European Forum on Quality Improvement in Health Care
}

\author{
21-23 March 2002 \\ Edinburgh, Scotland
}

We are delighted to announce this forthcoming conference in Edinburgh. Authors are invited to submit papers (call for papers closes on Friday 5 October 2001) and delegate enquiries are welcome.

The themes of the Forum are:

- Leadership, culture change, and change management

- Achieving radical improvement by redesigning care

- Health policy for lasting improvement in health care systems

- Patient safety

- Measurement for improvement, learning, and accountability

- Partnership with patients

- Professional quality: the foundation for improvement

- Continuous improvement in education and training

- People and improvement.

Presented to you by the BMJ Publishing Group (London, UK) and Institute for Healthcare Improvement (Boston, USA). For more information contact: quality@bma.org.uk or look at the website www.quality.bmjpg.com. Tel: +44 (0)20 7383 6409; fax: +44 (0)20 73736869 . 